MATEC Web of Conferences 10,06001 (2014)

DOI: $10.1051 /$ matecconf/ 20141006001

(C) Owned by the authors, published by EDP Sciences, 2014

\title{
Safety Assessment in Installation of Precast Concrete
}

\author{
S.N. Yashrri ${ }^{1}$, A. Hanizam ${ }^{2, a}$ \\ ${ }^{1,2}$ School of Housing, Building and Planning, Universiti Sains Malaysia, 11800, Penang, Malaysia
}

\begin{abstract}
This study was carried out to identify the safety aspects and the level of safety during the installation process in construction sites. A questionnaire survey and interviews were done to provide data on safety requirements in precast concrete construction. All of the interviews and the research questionnaire survey were conducted among contractors that are registered as class 1 to class 7 with the Construction Industry Development Board (CIDB) and class A to class G with Pusat Khidmat Kontraktor (PKK) in Penang. Returned questionnaires were analysed with the use of simple percentages and the Likert Scale analysis method to identify safety aspects of precast construction. The results indicate that the safety aspect implemented by companies involved in the precast construction process is at a good level in the safety aspect during bracing, propping, welding and grouting processes and at a very good level of safety in general aspects and safety aspects during lifting processes.
\end{abstract}

\section{Introduction}

Local workers currently not interested in entering the construction sector may change their stance if the above problem can be overcome. This in turn will lead to increased purchasing power of Malaysians and bring improvements in terms of economic and social culture. Changes in the construction sector effect of the usage advantages of IBS itself [1]. With the encouragement and support of CIDB and the government, in the future IBS will be fully utilized in the construction industry. Various parties are involved in construction using IBS, from component manufacturers through to the IBS contractor that installs the precast components. Accordingly, safety measures are required to ensure construction IBS is safe, so that a safe and clean construction can be achieved which is one of the advantages of IBS usage.

IBS is often misinterpreted as a system that is limited to buildings only. IBS is a system that can be widely applied in all types of construction. IBS is a system that includes any system construction using precast and pre-finished components available in large quantities from factories either far or close to the construction site resulting in a significant reduction in on-site labour [2]. In other words, it is a construction process that uses the techniques product or construction system components that involves installation of pre-fabricated building components at the construction site [3]. There are several processes of construction which still need to be conducted at the construction site using precast concrete components which start with proper planning and preparatory works, setting out, stabilizing the component with bracing or propping, lifting work, placing the component and component jointing with welding or grouting work. As with conventional construction, any construction using precast components is not spared from danger during construction work [4].

\footnotetext{
${ }^{a}$ Corresponding author: hanizam@usm.my
} 


\section{Data Collection}

The study population consisted of precast concrete construction among contractors that are registered as class 1 to class 7 with the Construction Industry Development Board (CIDB) and class A to class $\mathrm{G}$ with Pusat Khidmat Kontraktor (PKK) in Penang. Random sampling was conducted amongst the companies that are in the population. From the collection of the data from CIDB, there were about 20 contractor companies of precast concrete construction in the study area. The questions are divided into four parts. Part A is related to the background of the respondents, the designation, the type of company and the years of working experience involved in precast construction projects. Part B is related to the proper planning and preparation works before the installation process of the components begins. Part $\mathrm{C}$ is related to safety levels practiced by the employer during the installation process carried out on site. Part D is related to the safety aspects during component installation, with regard to the technical requirements and procedures that are usually practiced in the construction of precast concrete. Part D focuses on the general safety and requirements for the crane operation during installation of precast concrete components performed on site.

\section{Results and Discussions}

A total of 80 questionnaires were distributed to respondents around the state of Penang for construction projects using precast concrete, and as a result of the circulation, 56 respondents answered the questionnaire. The number of questionnaires that were answered is very satisfying which is $70 \%$ of the total.

\subsection{Planning and Preparatory work}

The bar chart in Figure 1 shows that almost all the respondents with $86 \%$ score to the mean of 4.85 in scale due to strongly agreed that is important to have proper planning and preparatory works to have efficient and quality installation. The value score for "installation procedures have to follow the installation requirement that is specified for the installation of vertical and horizontal components" and the "importance of consideration work items and checklist before the installation work starts" resulted in mean score of level 4.7 and above. Based on the result, it can be concluded that the contractor's safety aspect of concern in Penang is proper planning and preparatory work, done before actual installation, with an extremely high level of safety on-site and efficient installation work.

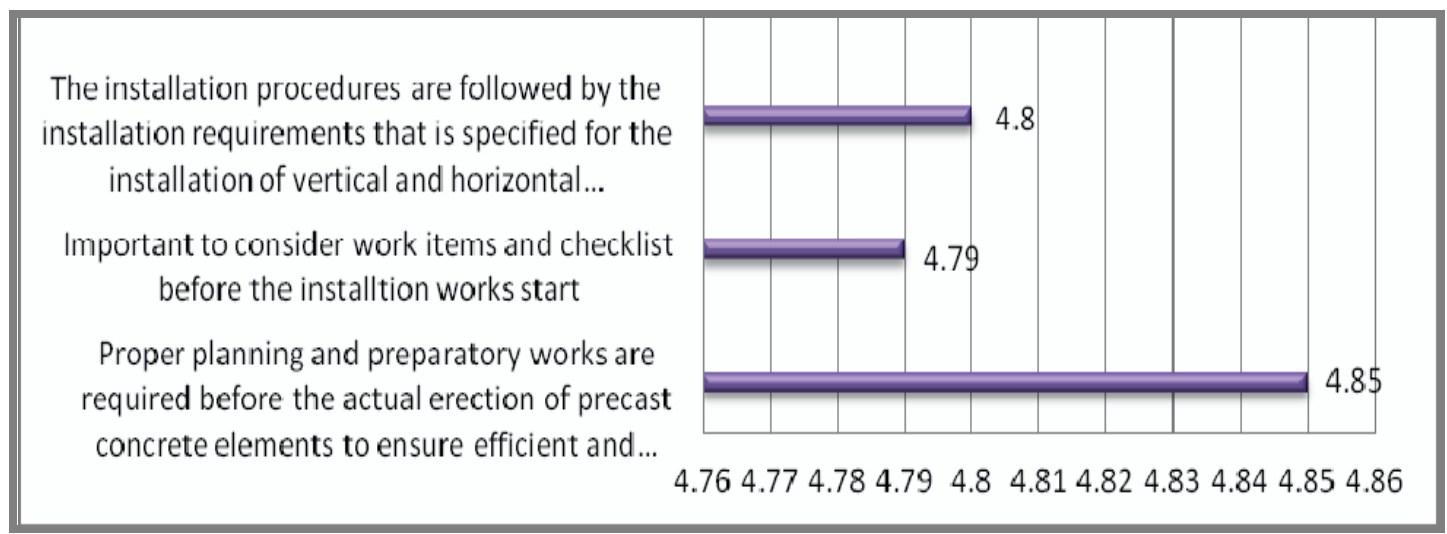

Figure 1. The mean score of preparatory works before actual installation

The bar chart in Figure 2 shows that the mean score of safety levels that are a concern to the contractors are at a good level on average. The highest shows that $86 \%$ of the respondents are at a scale of 4.86 scoring to the perception of safety awareness as an important aspect to the installer. 
While the perception of safety knowledge and the criteria in Penang have the same percentage of $68 \%$ with 4.68 mean scale. The satisfaction with the safety level at site currently and the effectiveness of safety level due to workers attitude during installation both score above the mean of 4.0

\subsection{Safety level of installation process}

Satisfaction with the safety level in site project currently Workers attitude affect the safety level during

installation work
The criteria of PPE should be complied with consensus standard

Knowledge about Personal Protective Equipment (PPE) should be provide to obtain construction project

Safety awarenes is a very important aspect to precast concrete installation workers

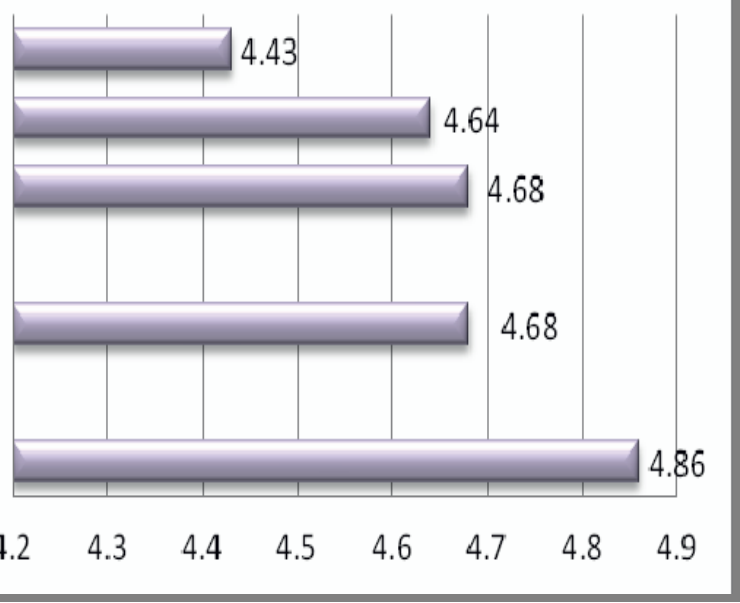

Figure 2. The mean score of safety level on precast concrete installation

It can be seen that almost all the respondents gave positive feedback in relation to the provision of safety equipment for their workers in order to carry out the installation works more safely. The comparison that can be made between the results from Figure 2 and Figure 3 are when proper planning and preparatory work is at a very good in level then the level of safety during the installation process is as a result, higher in relation to levels of awareness, satisfaction and knowledge.

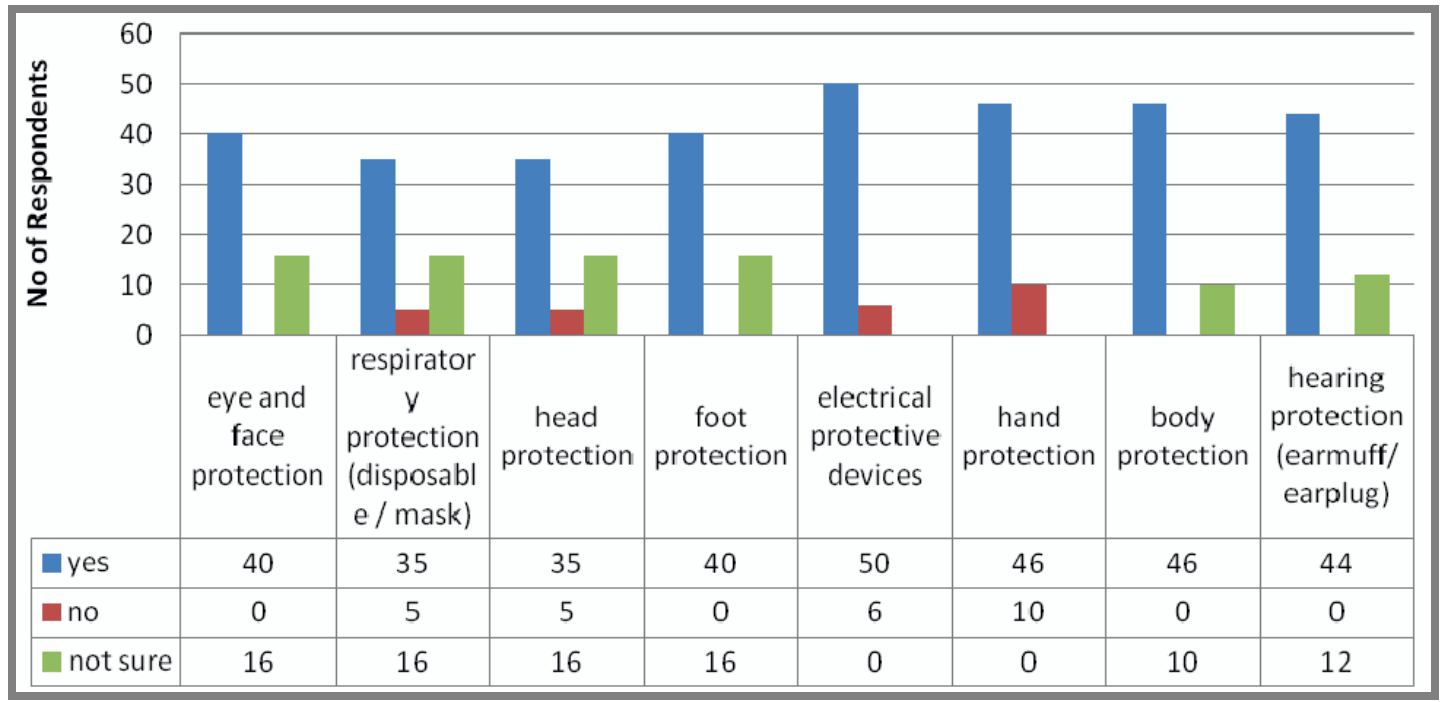

Figure 3. The numbers of respondent that provide PPEs to their workers

A high percentage of respondents also highlighted that the contractor or the employer does not have any problems in training workers to follow the safety procedures as they are aware of the importance of training workers to have a responsible and disciplined manner in that this attitude can 
enhance the level of safety during installation work. In addition, the employer is aware of the importance of safety during the installation works where the tool box meeting is carried out systematically thus showing a very good level of safety [5]. This is to ensure hazard control measures are successfully implemented: a detailed explanation must be given to workers on safety procedures that are practiced by the company. This can be accomplished by conducting Safety Talks or Tool Box Meetings operated by qualified personnel such as the Safety Officer.

\subsection{The safety aspect and the requirements of installation process}

From Figure 4, the safety aspects show a good level. The percentage shows a high level of awareness of the need for written permission from the Safety Supervisor in certain circumstances, in Penang scoring $68 \%$. The remaining $37 \%$ of respondents stated that propping take off permission is required to be obtained from the Project Design Engineer. This can be related to the finding that almost all respondents (75\%) in Penang as mentioned above, provide Personal Protective Equipment (PPE) to their workers and evidently get good feedback that the workers use every item of Personal Protective Equipment (PPE) that has been provided to them.

Before starting lifting the components, a danger zone for crane operation must be provided so that the crane has sufficient space to work to avoid any unwanted accidents and the operation is safely conducted. Only those involved in the installation work of precast components may be in the area [6].

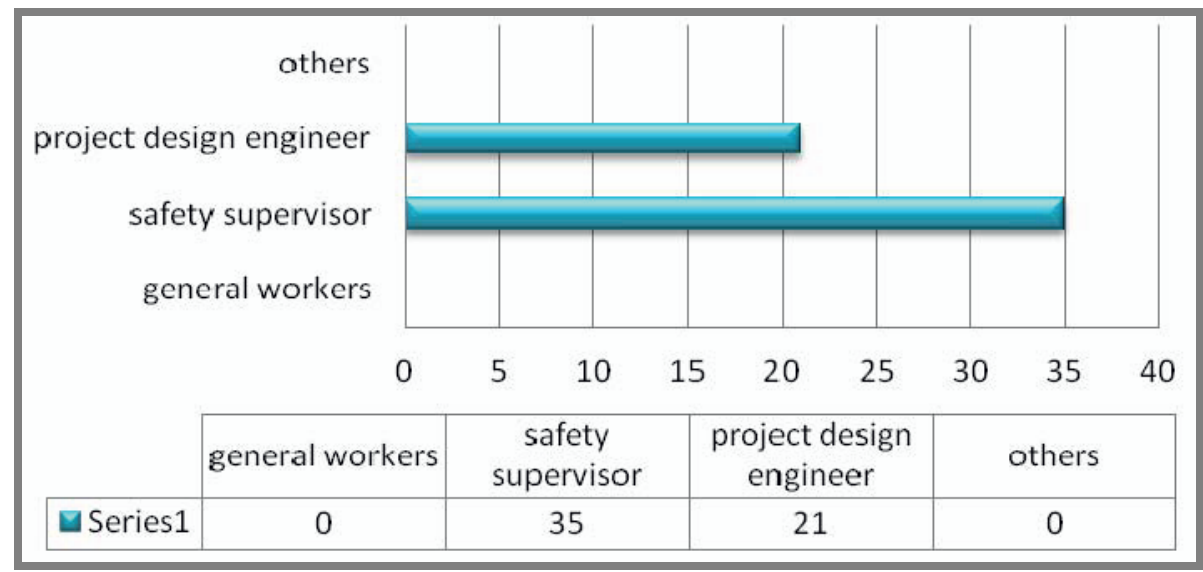

Figure 4. The qualified personnel given written permission to allow for take off the propping

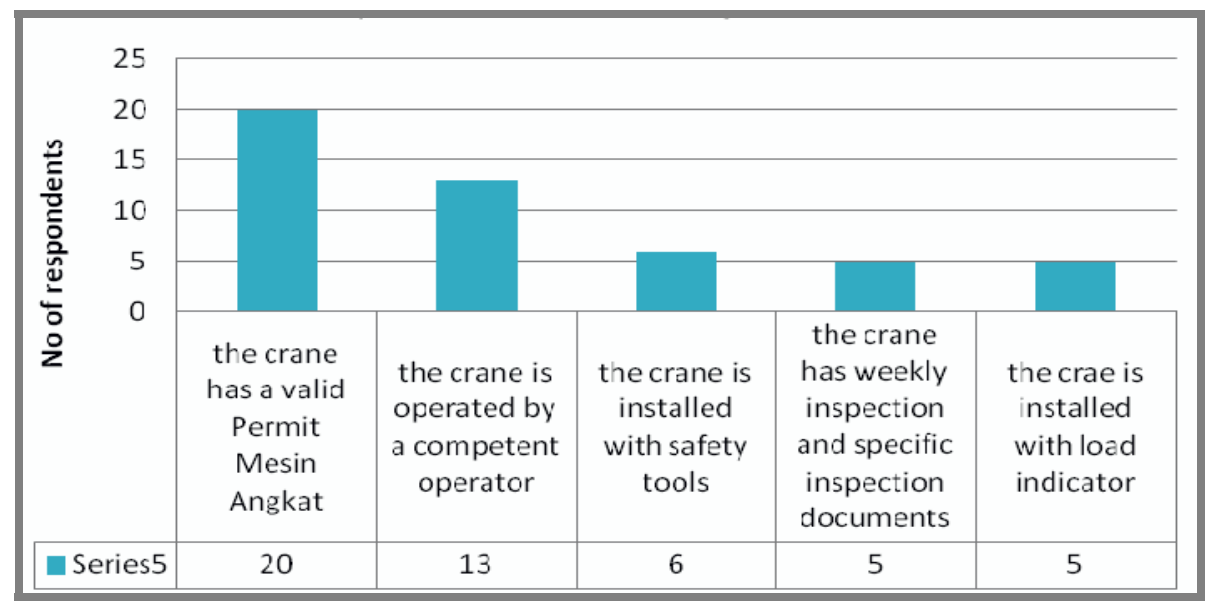

Figure 5. The operational requirements for the crane 
Bracing or propping devices should be checked each time before they are used to ensure that the instrument is in good condition. Bracing can only be opened after the last extension works were carried out; either grouting method or welding. In addition, the brace can only be opened after obtaining instructions from the Erection Project Engineer [7].

Before being allowed to operate cranes, several things need to be checked which is the site for the crane work, communication devices such as walkie-talkies, conditions and heavy components to be lifted, the location for the installation of cranes and components as well as the capacity of the crane operating radius [8]. From the questions asked, all respondents said that the inspection is done every time before a crane operation. To enable the cranes to operate at the site, a few things need to be obtained, or should be present on the crane.

The crane must also only be operated by qualified persons, who have received training to operate a crane. They should be registered through DOSH to obtain the operating license for a crane. Another recommended procedure is to have on a crane a document confirming that weekly and periodic inspections have been performed. There are also some other procedures that need to be installed on the crane such as a hoist over the cut outs, and over the boom cut out, as well as a chart that shows the load that can be supported by the crane [8].

From the Figure 5 shown, most respondents in Penang agreed that the crane should have these important procedures. $40 \%$ of respondents stated that the crane must have a valid Permit Mesin Angkat (PMA), and 27\% indicated that the crane must be operated by a competent operator. The remaining $12 \%$ of respondents expressed that a crane must be fitted with appropriate safety devices, while $20 \%$ of the respondents stated that the crane has a weekly inspection and specific inspection documents and the crane is installed with a load indicator. It can be concluded that the safety aspects of crane operations at the construction site have a good percentage which is $51 \%$ of the 49 respondents have all of the requirements. Only $29 \%$ of respondents stated that the crane must have a valid Permit Mesin Angkat (PMA) and operated by a competent operator while the remaining 14\% only have PMA. The remaining 7 respondents out of 56 stated other factors which are not included in the requirements by DOSH.

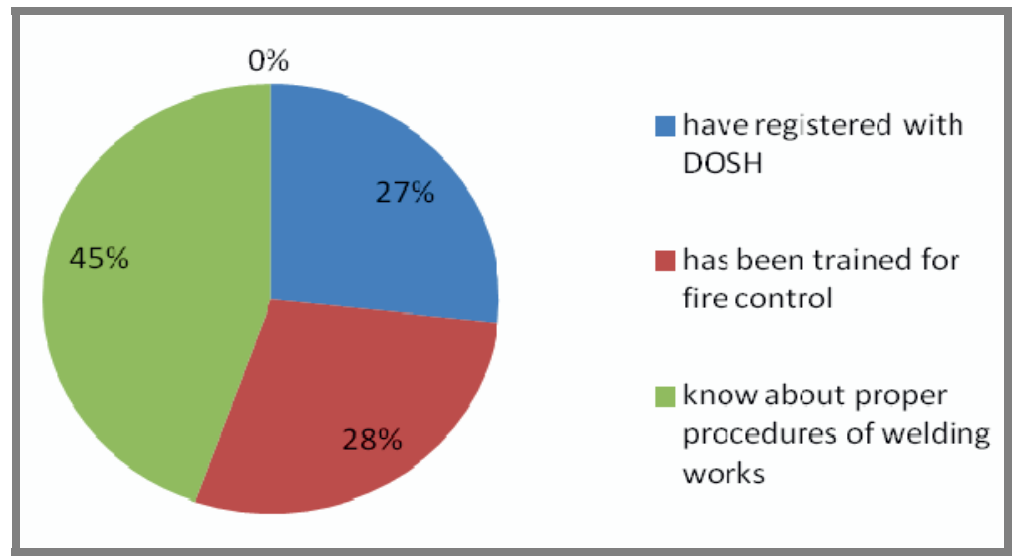

Figure 6. The percentage of respondents concern of requirements for welding worker

Figure 6 shows the percentage of respondents concern regarding the eligibility requirements for welding workers in Penang. Based on the pie chart, only $27 \%$ of respondents indicated their welder registered with DOSH, $28 \%$ of respondents said that their workers had been trained for fire control and the rest $45 \%$ of respondents indicated that employees received training on how to weld.

For the safety aspect of welding work, the majority of respondents indicated that workers received training on how to do the technique of welding. To ensure that the welding work is done properly, only a qualified welder is allowed to perform welding work. Welders eligible are those who have registered with the Department of Occupational Safety and Health (DOSH). These welders also need to receive training for fire control [8]. It can be concluded that the safety aspect for the welding 
work is at an extremely good level where welders doing the welding works meet the criteria such as, required to be registered with the Department of Occupational Safety and Health (DOSH), have received training for fire control, and know the ways of proper welding and the work is done safely.

\section{Conclusions}

As in conventional construction, construction using precast is not spared from dangers or hazards during construction work. The safety aspects on precast concrete installation processes have been identified. The results indicate that the safety measures implemented by the companies involved in precast construction projects is at a good level whether during bracing work, propping work, welding work and grouting work and the study found that general safety and safety during lifting processes are at a very good level. In conclusion, this study has boosted knowledge, and detailed information is given with regard to the safety aspect in Industrialized Building Systems using precast concrete and improvements in awareness on the road to zero percent of accidents in Penang. From the study, the safety aspects implemented by companies involved in the precast installation process in Penang, were at an extremely high level.

\section{References}

1. CIDB Malaysia, IBSDigest January - March 2005, CIDB Malaysia, 2005, pp: 4-8

2. Hafizal Mahadi, Aspek Kualiti Dalam Pembinaan Bangunan Menggunakan Konkrit Pra-Tuang, BSc Degree, UTM, 2007, pp: 43-61

3. N.Y. Maamor, Safety Aspect in Installation Industrialized Building System (IBS) Component, 3. Research Study for Bachelor Degree in Civil Engineering, UMP, 2007, pp: 65-69

4. Precast Technics Sdn Bhd, Manual Kaedah Kerja Dan Lampiran Jaminan Kualiti (QA/QC) Untuk Sistem "Simplified Precast Building” (The SPB System), Precast System Specialist, 2012

5. A. Wetmore, Centers for Disease Control and Prevention Coffee Break: Using Likert Scales in Evaluation Survey Work, CDC, Atlanta, 2012, pp: 2-9

6. Workplace Health and Safety Queensland (WHSQ), Tilt-up and Pre-cast Construction: Industry Code of Practice, Queensland Government, Department of Industrial Relations, 2003, pp: 1-12

7. CIDB Malaysia, Industry Standard: Standard for Handling Stacking, Transportation and Erection of Precast Concrete Elements, CIDB Malaysia, 2009, pp: 22-34

8. Department of Occupational Safety and Health (DOSH), Guidelines for Public Safety and Health at Construction Sites, Ministry of Human Resources Malaysia, 1994, pp: 11-18 